\title{
Study on Fermentation Technology of Maca Apple Compound Enzyme
}

\author{
Danmin Fan $^{1,2}$, Zhilong Yang ${ }^{2}$ \\ ${ }^{1}$ Research Center of Characteristic Agriculture of Northwest Yunnan Plateau, Lijiang, Yunnan Province, \\ China \\ ${ }^{2}$ Lijiang Teachers College, Lijiang, Yunnan Province, China
}

Keywords: Maca; apple; compound enzyme; fermentation process.

\begin{abstract}
The fermentation process of Maca apple compound enzyme is studied in this paper. Maca and apples are main raw materials in this experiment. Through the single factor experiment, researchers analyze the influences of 3 main factors, namely the raw material ratio, the strain ratio and the sugar amount on the fermentation quality of Maca apple compound enzyme from the perspectives of total phenol content, DPPH radical scavenging activity and hydroxyl radical scavenging ability. The experimental results are analyzed through orthogonal test and sensory evaluation, in order to find the best production process of Maca apple compound enzyme. The experimental results show that if the yeast and Bifidobacterium ratio is 3:1, the Maca and apple ratio is 1:12, and 30\% of sugar is added, the best Maca apple compound enzyme will be produced after fermentation for 60 days. The total phenol content in the fermented enzyme can reach $1.71 \mathrm{mg} / \mathrm{g}$; DPPH free radical scavenging capacity can reach 88\%; hydroxyl free radical scavenging capacity can reach $79 \%$. The compound enzyme also has the best sweet and sour taste of Maca and apple, as well as the best aroma of Maca.
\end{abstract}

\section{Introduction}

Maca (Lepidium meyenii Walp.) is native to Peru, South America. It grows in Andes Mountain at about 3000-4000m kilometers above the sea level, and is known as the "Peru ginseng" [1]. As a kind of natural medicine and health care product, Maca has attracted more and more attention from botanical and medical experts all over the world [2]. It is also widely used in food processing. Maca contains not only rich nutrients, but also various active ingredients, such as Maca amide, Macaenes, alkaloids and glycosides with sulfur. Maca can enhance human immunity, help human to recover rapidly, to remove physical fatigue and improve fertility; it also has functions of anti-oxidation and endocrine regulation [3-5]. Apple (Malus pumila) is a kind of fruit. It is belongs to malus, Maloideae, Rosaceae. Apple trees are deciduous trees. Apple fruits are rich in minerals, vitamins, polysaccharides, protein and fat; they also contain a large number of microelements [6]. As a common fruit in our daily consumption, apples have functions of anti aging, anti oxidation and strengthening immunity.

Fermentation technique of edible enzymes means that, by using strains like lactobacillus and saccharomycetes, fruits and vegetables can become liquid or solid food products which are rich in lipase, amylase, protease and metabolites like lactic acid and acetic acid [7]. Enzyme, also known as "ferment", is a kind of "metabolite" secreted by probiotics. It is the catalyst of enzyme which is composed of protein [8]. Enzyme has health functions like anti-aging, antibacterial, anti-inflammatory, blood purifying [9] and immunity improvement. In this paper, Maca and apple are used as main raw materials to study the changes of total phenol content, DPPH radical scavenging capacity and hydroxyl radical scavenging capacity in natural fermentation process, in order to provide theoretical and technological basis for further development and the utilization of Maca enzyme products. 


\section{Research Material and Methods}

\subsection{Research materials and equipment.}

Maca used in the experiment is bought in Lijiang; apple and sugar are bought in Li Ke Long supermarket of Lijiang; high active dry yeast (high temperature resistance) used in the experiment is produced by Hubei ANGEL YEAST CO.; HR7632 beating machine is produced by Guangzhou PHILPS Household Appliances Co. Ltd.; BS210S electronic scales is produced by Beijing Sartorius Scientific Instrument Co. Ltd.; UV-visible light spectrophotometer is produced by Shanghai Techcomp Scientific Equipment Co. Ltd; handhold saccharimeter -VBR90A (WZ109) is produced by Zhengzhou Nanbei Instrument Co. Ltd.; glass fermentor is bought in Lijiang; DZKW-4 electric thermostatic water bath kettle is produced by Linmao Technology (Beijing) Co., Ltd.; CUM180 universal grinder is produced by Weifang ALPA Powder Technology \& Equipment Co. Ltd; FLOM laboratory water purification machine is produced by Qingdao FLOM Co. Ltd.

\subsection{Research method.}

Process flow

Maca $\rightarrow$ smash $\rightarrow$ sifting $\rightarrow$ distilled water $\rightarrow$ microwave gelatinization $\rightarrow$ cooling

Apple $\rightarrow$ peel $\rightarrow$ clean $\rightarrow$ beat $\rightarrow$ mix $\rightarrow$ add water $\rightarrow$ adjust $\mathrm{PH}$ value and water $\rightarrow$ add sugar $\rightarrow$ add strain $\rightarrow$ fermentation for 60 days $\rightarrow$ filter $\rightarrow$ Maca apple complex enzyme

Key points of operation. Preprocessing of Maca and apples. Apples should be peeled and rinsed with sterile water, and then cut and beat by sterilized fruit crushing and pulping machine; then sterile water is added according to the volume ratio of 1:1. Maca should be smashed and added into water according to the volume ratio of $1: 1$; after mixing, the material is put into laboratory microwave for gelatinization. After heating with $600 \mathrm{~W}$ for 1 minute, Maca is taken out and cooling stand-by [10]. After mixing Maca paste with apple pulp, pure water is added with the mass ratio of $1: 1$, and then fermentation process begins.

Addition of strains. After mixing the Maca paste and apple pulp, the material is put into sterilized fermentation tank and added with sterile water according to the volume ratio of $1: 1$; $\mathrm{PH}$ value is adjusted to $6-7$; then $30 \%$ of sugar is added. Strains are mixed with the proportion of $1.2 \%$ of yeast and Bifidobacterium. Then 20 times sterile water (containing 2\% of sugar) is added in constant temperature of 30 degree for 20-30 minutes and stir evenly. When the volume increases to 2-3 times, the strain is added to the fermentation tank, then mixed and sealed for fermentation. [11]

Control of fermentation process. The material is then sealed for fermentation at room temperature for 60 days. At the first 3 days, the material is stirred once a day. Then the $\mathrm{pH}$ value and alcoholic strength are tested after every 7 days. When alcoholic strength is $2 \%$ vol, the material is filtrated and sealed. The pre-fermentation process is completed. Afterwards, the $\mathrm{pH}$ value is tested after every 7 days. When the $\mathrm{pH}$ value of fermentation liquid is 4 , the post-fermentation process is completed. The clear liquid obtained is the Maca apple compound enzyme.

Single factor test design. The proportions of raw materials of Maca and apple are 1:8, 1:10, 1:12, 1:14 and 1:16 respectively. The proportions of yeast and Bifidobacterium are 1:3, 1:2, 1:1, 2:1 and 3:1 respectively. Sugar addition amounts are 15\%, 20\%, 25\%, 30\% and 35\% respectively. Results single variable test is performed on each single variable. After the total single factor test, total phenol content, DPPH radical scavenging capacity and hydroxyl radical scavenging capacity are determined.

Orthogonal optimization of Maca apple compound enzyme. Through the analysis of 3 single factors of Maca and apple mass ratio (A), yeast and Bifidobacterium ratio (B) and sugar content (C), the orthogonal design of L9 (34) is used. The experimental design can be seen in table 1. 
Table 1 Orthogonal test factor level

\begin{tabular}{llll}
\hline level & factor & & \\
\hline Level & A Maca powder: apple pulp (g:g) & B yeast: Bifidobacterium (g:g) & C sugar content (\%) \\
1 & $1: 12$ & $1: 1$ & $25 \%$ \\
2 & $1: 14$ & $2: 1$ & $30 \%$ \\
3 & $1: 16$ & $3: 1$ & $35 \%$ \\
\hline
\end{tabular}

Determination of the total phenol content [12]. $0.1 \mathrm{ml}$ sample is added to $1 \mathrm{ml}$ with distilled water; $2 \mathrm{ml}$ Folin reagent is added to the mixture. After mixing, the liquid is placed for 3 minutes in static solution. Then $2 \mathrm{ml}$ sodium carbonate solution with mass fraction of $10 \%$ is added. The liquid is placed for 1 hour at 25 degrees. The absorbance value is measured at the distance of $760 \mathrm{~nm}$. The distilled water is taken as a blank control. The content of total phenols in Maca apple complex enzyme is expressed as gallic acid for equivalent. According to the standard curve linear equation $y=0.036 x-0.0145\left(R^{2}=0.9933\right)$, in which $x$ represents the sample concentration, and y represents the absorbance value, the total phenol content in Maca apple compound enzyme can be calculated.

Determination of DPPH free radical scavenging ability [13]. 40ul sample is added to $4 \mathrm{ml}$ $0.1 \mathrm{mmol} / \mathrm{l} \mathrm{DPPH}$ - Formaldehyde Solution, and then 450ul 50mmol Tris-HCl butffer (7.4) is added, and placed for 30 minutes at the constant temperature of 25 degree. Deionized water is mixed in the solution. The absorbance is measured at the wavelength of $517 \mathrm{~nm}$.

DPPH free radical scavenging capacity $(\%)=\left[\left(\mathrm{A}_{0}-\left(\mathrm{A}_{1}-\mathrm{A}_{2}\right)\right) / \mathrm{A}_{0}\right] \mathrm{X} 100$

In this formula, $A_{0}$ stands for the absorbance of the blank control solution; A1 stands for the absorbance of the sample tube; $A_{2}$ stands for the absorbance of the sample base tube.

Hydroxyl radical scavenging ability [14]. 100, 150, 200, 250 and 300ul samples are added to $6 \mathrm{mmol} / \mathrm{l} \mathrm{H}_{2} \mathrm{O}_{2}$, and then $0.6 \mathrm{~mL} 20 \mathrm{mmol} / \mathrm{l}$ sodium salicylate and $2 \mathrm{ml} 1.5 \mathrm{mmol} / \mathrm{l}$ ferrous sulfate is added for 1 hour water bath at the constant temperature of 37 degrees. The deionized water is used as the reference solution, and VC is used as the control. The absorbance is measured at 562nm, and IC50 is calculated.

The hydroxyl radical scavenging capacity $(\%)=\left[\left(\mathrm{A}_{0}-\left(\mathrm{A}_{1}-\mathrm{A}_{2}\right)\right) / \mathrm{A} 0\right] \mathrm{X} 100$

In this formula, $A_{0}$ stands for the absorbance of the blank control solution; $A 1$ stands for the absorbance of the sample tube; $A_{2}$ stands for the absorbance of the sample base tube.

Determination of other indexes. The content of soluble solids is determined through a handheld refractometer. Total acid content is determined according to GB/T 12456-2008 [15] by titration method; total bacterial count is determined according to microbial indicators GB 4789.2-2010[16]; coliform bacteria are determined according to GB 4789.3-2010[17]; pathogenic bacteria are determined according to GB 29921-2013 [18].

Sensory quality evaluation [19]: the sensory quality of Maca apple compound enzyme is evaluated by 15 students majoring in food biotechnology, and the standards of evaluation are shown in Table 2 .

Table 2 Sensory quality evaluation standards of Maca apple compound enzyme

\begin{tabular}{lll}
\hline index & Evaluation standard & point \\
\hline Color (20 points) & yellowish-brown, bright & $16 \sim 20$ \\
& light brown, slightly turbid & $10 \sim 15$ \\
& dark brown or black & $0 \sim 9$ \\
State (20 points) & clear, uniform & $16 \sim 20$ \\
& relatively clear, uniform & $10 \sim 15$ \\
Aroma (30 points) & turbidity, opaque & $0 \sim 9$ \\
& strong Maca smells & $20 \sim 30$ \\
& light Maca smells & $10 \sim 19$ \\
Taste (30 points) & too light or strong Maca smells & $0 \sim 9$ \\
& moderate taste of sweet and sour & $20 \sim 30$ \\
& taste sour or sweet; alcohol flavor & $10 \sim 19$ \\
& too sour or too sweet & $0 \sim 9$ \\
\hline
\end{tabular}




\subsection{Data processing.}

The results of single factor test are analyzed by Excel 2007 software; the orthogonal design assistant II 3.1 software is also used to analyze data.

\section{Research Results and Analysis}

\subsection{Effects of raw material ratio on the compound enzyme.}

The proportion of Maca and apple directly affects the overall quality of the compound enzyme. The effects of different raw material ratio on the product are shown in table 3.

Table 3 Effects of raw material ratio on fermentation of compound enzyme

\begin{tabular}{lllll}
\hline $\begin{array}{l}\text { Maca: apple } \\
\text { quality ratio }\end{array}$ & $\begin{array}{l}\text { Total phenol } \\
\text { content (mg/g) }\end{array}$ & $\begin{array}{l}\text { DPPH radical } \\
\text { scavenging } \\
\text { capacity (\%) }\end{array}$ & $\begin{array}{l}\text { hydroxyl radical } \\
\text { scavenging capacity } \\
(\%)\end{array}$ & $\begin{array}{l}\text { Sensory score / } \\
\text { points }\end{array}$ \\
\hline $1: 8$ & 1.37 & $79 \%$ & $74.6 \%$ & 78 \\
$1: 10$ & 1.4 & $80.3 \%$ & $77 \%$ & 79 \\
$1: 12$ & 1.38 & $83 \%$ & $79.3 \%$ & 83 \\
$1: 14$ & 1.43 & $86.2 \%$ & $79.6 \%$ & 85 \\
$1: 16$ & 1.57 & 84.5 & $79.2 \%$ & 89 \\
\hline
\end{tabular}

Table 3 shows, with the increasing of Maca and apple quality ratio, total phenol content, DPPH radical scavenging activity, hydroxyl radical scavenging ability and sensory score show an upward trend. That is mainly because apples are rich in polyphenols and flavonoids contents, while Maca powder has relatively less substances. Thus, with the increase of Maca and apple quality ratio, total phenol content, DPPH radical scavenging activity and hydroxyl radical scavenging ability increase gradually. Sensory score increase because Maca contains a lot of mustard oil, squalene and Maca amide. The smell of Maca is quite strong. With the increasing of apple, the smell of Maca is diluted, and the sensory score increases.

\subsection{Effects of strain ratio on the compound enzyme.}

Effects of strain ratio on the compound enzyme are show in table 4.

Table 4 Effect of strain ratio on compound enzyme

\begin{tabular}{lllll}
\hline $\begin{array}{l}\text { Yeast and } \\
\text { bifidobacterium } \\
\text { quality ratio }\end{array}$ & $\begin{array}{l}\text { Total phenol } \\
\text { content (mg/g) }\end{array}$ & $\begin{array}{l}\text { DPPH radical } \\
\text { scavenging } \\
\text { capacity (\%) }\end{array}$ & $\begin{array}{l}\text { hydroxyl radical } \\
\text { scavenging capacity } \\
(\%)\end{array}$ & $\begin{array}{l}\text { Sensory score / } \\
\text { points }\end{array}$ \\
\hline $1: 3$ & 1.39 & $80 \%$ & $75 \%$ & 80 \\
$1: 2$ & 1.4 & $80.3 \%$ & $75.3 \%$ & 79 \\
$1: 1$ & 1.4 & $80.9 \%$ & $75.1 \%$ & 81 \\
$2: 1$ & 1.43 & $84.1 \%$ & $77.4 \%$ & 84 \\
$3: 1$ & 1.47 & $85.3 \%$ & $80.1 \%$ & 87 \\
\hline
\end{tabular}

Table 4 shows, if the proportion of yeast and Bifidobacterium lies in 1:1 to 1:3, the total phenol content, the DPPH radical scavenging and free radical scavenging capacities, as well as the sensory scores do not change greatly. With the increasing of yeast ratio, the total phenol content, the DPPH radical scavenging and hydroxyl radical scavenging capacities, as well as the sensory scores gradually increase. This is mainly because with the increasing of yeast, residual sugar content in compound enzyme decreases. The total phenol content, as well as the DPPH radical scavenging and hydroxyl radical scavenging capacities mainly depend on the transformation of yeast. At the same time, lower residual sugar content means the moderate sweet and sour taste, which leads to higher 
sensory scores.

\subsection{Effects of sugar content on the compound enzyme.}

Effects of sugar content on the compound enzyme are shown in table 5.

Table 5 Effects of sugar content on the compound enzyme

\begin{tabular}{ccccc}
\hline $\begin{array}{c}\text { Sugar addition } \\
(\%)\end{array}$ & $\begin{array}{c}\text { Total phenol } \\
\text { content (mg/g) }\end{array}$ & $\begin{array}{c}\text { DPPH radical } \\
\text { scavenging } \\
\text { capacity (\%) }\end{array}$ & $\begin{array}{c}\text { hydroxyl radical } \\
\text { scavenging capacity } \\
(\%)\end{array}$ & $\begin{array}{c}\text { Sensory score / } \\
\text { points }\end{array}$ \\
\hline $15 \%$ & 1.33 & $79 \%$ & $67 \%$ & 76 \\
$20 \%$ & 1.48 & $82.3 \%$ & $71 \%$ & 79 \\
$25 \%$ & 1.56 & $84.7 \%$ & $74.7 \%$ & 82 \\
$30 \%$ & 1.63 & $85.9 \%$ & $77.2 \%$ & 85 \\
$35 \%$ & 1.71 & $87.1 \%$ & $78.4 \%$ & 89 \\
\hline
\end{tabular}

Table 5 shows, with the increasing of sugar content, total phenol content, DPPH radical scavenging activity, hydroxyl radical scavenging ability and sensory score show an upward trend. This is mainly because sugar provides a lot of enzymes for the breeding of yeast, and improves free radical scavenging capacity. At the same time, the final acidity of the fermentation is too high, resulting in heavy sour flavor which seriously affects the sensory score. Sugar is conducive to the improvement of enzyme taste.

\subsection{Analysis of the orthogonal test results.}

In order to determine the key parameters of the 3 factors, 3 factors 3 levels L9 (33) orthogonal test is designed. Material ratio, strain ratio and sugar content are 3 factors influencing the optimal fermentation of Maca apple compound enzyme. Orthogonal test results are shown in table 6.

Table 6 Orthogonal test results

\begin{tabular}{|c|c|c|c|c|c|c|c|}
\hline \multirow[b]{2}{*}{$\begin{array}{l}\text { test } \\
\text { no. }\end{array}$} & \multicolumn{3}{|l|}{ Factor } & \multirow{2}{*}{$\begin{array}{l}\text { Total } \\
\text { phenol } \\
\text { content } \\
\text { (mg/g) }\end{array}$} & \multirow{2}{*}{$\begin{array}{l}\text { DPPH } \\
\text { radical } \\
\text { scavenging } \\
\text { capacity (\%) }\end{array}$} & \multirow{2}{*}{$\begin{array}{l}\text { hydroxyl } \\
\text { radical } \\
\text { scavenging } \\
\text { capacity (\%) }\end{array}$} & \multirow{2}{*}{$\begin{array}{l}\text { Sensory } \\
\text { score / } \\
\text { points }\end{array}$} \\
\hline & $\begin{array}{l}\text { A Maca: } \\
\text { apple } \\
\text { quality ratio }\end{array}$ & $\begin{array}{l}B \text { :Yeast } \\
\text { and } \\
\text { bifidobacte } \\
\text { rium } \\
\text { quality } \\
\text { ratio }\end{array}$ & $\begin{array}{l}C: \text { Sugar } \\
\text { content } \\
(\%)\end{array}$ & & & & \\
\hline 1 & $1: 12$ & $1: 1$ & $25 \%$ & 1.45 & $79 \%$ & $63 \%$ & 78 \\
\hline 2 & $1: 12$ & $2: 1$ & $30 \%$ & 1.43 & $79 \%$ & $67 \%$ & 80 \\
\hline 3 & $1: 12$ & $3: 1$ & $35 \%$ & 1.46 & $83 \%$ & $68 \%$ & 82 \\
\hline 4 & $1: 14$ & $1: 1$ & $30 \%$ & 1.56 & $82 \%$ & $71 \%$ & 81 \\
\hline 5 & $1: 14$ & $2: 1$ & $35 \%$ & 1.58 & $84 \%$ & $74 \%$ & 85 \\
\hline 6 & $1: 14$ & $3: 1$ & $25 \%$ & 1.67 & $85 \%$ & $73 \%$ & 85 \\
\hline 7 & $1: 16$ & $1: 1$ & $35 \%$ & 1.79 & $83 \%$ & $77 \%$ & 82 \\
\hline 8 & $1: 16$ & $2: 1$ & $25 \%$ & 1.78 & $86 \%$ & $78 \%$ & 88 \\
\hline 9 & $1: 16$ & $3: 1$ & $30 \%$ & 1.85 & $88 \%$ & $79 \%$ & 89 \\
\hline$K_{1}$ & 240 & 241 & 251 & & & & \\
\hline$K_{2}$ & 251 & 253 & 250 & & & & \\
\hline$K_{3}$ & 259 & 256 & 249 & & & & \\
\hline$k_{1}$ & 80.00 & 80.33 & 83.67 & & & & \\
\hline$k_{2}$ & 83.67 & 84.33 & 83.33 & & & & \\
\hline$k_{3}$ & 86.33 & 85.33 & 83.00 & & & & \\
\hline$R$ & 6.33 & 5.33 & 0.67 & & & & \\
\hline
\end{tabular}

Table 6 shows that, the effects of various factors can be ranked as A > B > C, namely Maca and 
apple proportion has the greatest impact, followed by yeast and Bifidobacterium proportion, and then sugar addition. The best combination is A3B3C2, namely the Maca and apple ratio is 1:16; yeast and Bifidobacterium ratio is 3:1; $30 \%$ of sugar is added. Under these conditions, the total phenol content in the fermented enzyme can reach $1.85 \mathrm{mg} / \mathrm{g}$; DPPH free radical scavenging capacity can reach 88\%; hydroxyl free radical scavenging capacity can reach $79 \%$.

\subsection{Analysis of product quality indexes.}

Product sensory indicators. Color: yellowish brown, uniform and bright color. State: clear and transparent. Aroma: strong Maca aroma and fruity fragrance; harmonious aroma of Maca and apple. Taste: harmonious taste of Maca and the fruit, moderate, unique taste of sour and sweet.

Microbiological indexes

Table 7 Microbial indexes of the compound enzyme

\begin{tabular}{cl}
\hline Item & index \\
\hline Total bacterial count & $\leqq 10 \mathrm{CFU} / \mathrm{mL}$ \\
Escherichia coli flora & $<3 \mathrm{MPN} / 100 \mathrm{~mL}$ \\
Pathogenic bacterium & none \\
& \\
\hline
\end{tabular}

\section{Conclusions}

Through the single factor test, the orthogonal test analysis and the sensory test analysis, the optimum process of Maca apple compound enzyme is found. Ratio of Maca and apple should be 1:16; yeast and Bifidobacterium should be mixed according to the ratio of 3:1, and then $1.2 \%$ should be added for fermentation; sugar content should be $30 \%$. Under these conditions, the compound enzyme is produced as bright, yellow liquid with strong aroma, as well as pleasant, natural taste of sweet and sour. In this paper, Maca and apple are used as main raw materials to study the fermentation process of compound Maca apple enzyme, in order to provide some new perspectives and foundation for further processing of Maca and apple.

\section{Acknowledgement}

Fund Project: This paper is supported by Foundation for the Projects of Science and Technology Planning Program of Lijiang (Project No.: 2016LJSFK016); it is also supported by Foundation for Scientific Research Projects of Education Department of Yunnan (Project No.: 2016ZZX271).

\section{References}

[1] J. Rea, Maca (Lepidium Meyenii), in: B. Hernando, J. Leon (Eds.), Neglected Crops: 1492 from a Different Perspective, FAO-Plant Production and Protection Series, Rome, 1994, pp. 165-179.

[2] Y.L. Wang, Y.C. Wang, M.N. Brian, et al., Maca: an andeancrop with multi-pharmacological functions, J. Food Res Int. 40 (2007).

[3] L.J. Yu, W.W. Jin, MACA: International Fine Breed, Medical and Edible Dual Purpose Plant, Huazhong University of Science and Technology Press, Wuhan, 2003

[4] M. Ganzem, J. Zhao, I. Muhammad, et al., Chemical profiling and standardization of Lepidium meyenii (Maca) by reversed phase high performance liquid chromatography, J. Chem Pharm Bull. 50 (2002).

[5] Z.J. Yin, C.J. Yang, P.Y. Yin, et.al., Progresses in research of nutrition and efficacy of Maca, J. Yunnan Agricultural Science and Technology. 5 (2012).

[6]Chen H Y, Yen G C. Antioxidant activity and free radical-scavenging capacity of extracts from 
guava leaves, J. Food Chemistry. 101 (2007).

[7] J.Y. Liu, Z.W. Wang, Progress in microbial enzyme food research, J. Food and Fermentation Industries. 42 (2016).

[8] L. Zhang, J. Chen, et.al., Determination on multi-element distribution in apples through microwave digestion plasma emission spectrometry, J. Chinese Journal of Spectroscopy Laboratory. 26 (2009).

[9] J.W. Mao, Y.F. Wu, S. Fang, Progresses in microbial enzyme research, J. Fermentation Technology Communication. 39 (2010).

[10] X.H. Tu, H. Zhang, H. Zheng et.al., Optimization of Maca fermented wine technology, J. Food and Fermentation Industries. 41(2015).

[11] W.W. Zhan, X.Y. Wei, B.J. Gao, et.al., Process optimization of composite enzyme fermentation technology of lonicera edulis coconut, J. China Brewing. 36 (2017).

[12] F. Li, F.W. Wang, et al., Preliminary study on antioxidant activity of apple enzyme, J. Journal of Qingdao Agricultural University. 33 (2016).

[13] Z.L. Jiang, J.W. Mao, J. Huang, et al., Changes of antioxidant activity of grape ferment in natural fermentation process, J. Journal of Chinese Institute of Food Science and Technology. 14 (2014).

[14] Z.L. Jiang, X.Q. Liu, Z.Z. Wang, et al., Analysis of organic acid in vineal acid and its antioxygenic property, J. Journal of Chinese Institute of Food Science and Technology. 17 (2017).

[15] National Technical Committee on Food Industry Standardization Administration of China, Determination of Total Acid in Food, Standards Press of China, Beijing, 2008.

[16] National Food Safety Standard, Food Microbiological Examination: Determination of Total Acid in Bacterial Colony: GB4789.2-2010, Standards Press of China, Beijing, 2010.

[17] National Food Safety Standard, Food Microbiological Examination: Enumeration of Coliforms, GB4789.3-2010, Standards Press of China, Beijing, 2010.

[18] National Food Safety Standard, Pathogen Limits for Food, GB29921-2013, Standards Press of China, Beijing, 2013.

[19] L.S. Feng, D.M. Fan, Exploration of Maca and Pu'er tea compound beverage, J. Storage and Process. 17 (2017). 